\title{
Social legitimacy of private tutoring: an investigation of institutional and affective educational practices in India
}

\author{
Achala Gupta* \\ Department of Sociology, University of Surrey, UK
}

\begin{abstract}
While a growing body of research shows the prevalence of private tutoring in India, the ways in which these informal educational setups gain social legitimacy remains largely unclear. To redress this gap in the scholarship, this article investigates institutional and affective tutoring practices, in relation to formal schooling. It draws on the perspectives of tutors, school teachers, teacher-tutors, students and their parents, produced through an educational ethnography conducted in Dehradun (India) in 2014-15. In so doing, this article shows that strategic adoption (adhering to formal education practices) and tactical deviation (diverging from typical schooling norms) are central to tutoring centres' attempt to project themselves as academically relevant and desirable spaces for teaching and learning. By offering a nuanced understanding of the interactions between formal (schools) and informal (tutoring provisions) educational institutions, it argues that private tutoring serves as a critique of formal schooling in the empirical context.
\end{abstract}

Keywords: shadow education, private tutoring; schooling practices; social legitimacy; India

\section{Introduction}

Private tutoring - a globally pervasive phenomenon, also known as 'shadow education', 'supplementary education', 'outside-school edu-businesses', or 'coaching classes' - refers to a privatised system of education delivery that provides targeted educational services for students to excel in the formal assessment system (see Bray, 2017). The demand for tutoring support is often framed as a consequence of rising credentialism - a social condition in which 'competition for credentials [serves] as a primary determinant of modern stratification systems' - across societies (Brown, 2001; see, Baker, 2014). Tutoring, in the context of credentialism, is deemed as a parental strategy to provide their children with resources to succeed in increasingly competitive educational systems (Sriprakash, Proctor, \& Hu, 2016 - the authors discuss an Australian case of ethnic minority parents investing in tutoring support; also see, Park, Byun, \& Kim, 2011 for the Korean case, for example). Since socioeconomically advantageous groups are more likely to benefit from the valuable educational resources that tutoring provisions claim to offer (as families in these

\footnotetext{
* Email: achala.gupta.01@gmail.com
} 
groups not only can afford these services, but also, they are capable of paying high prices for better quality of these provisions), private tutoring exacerbates social inequalities in accessing perceived quality of education (see, Bray, 2017).

Tutoring businesses not only influence parental investment in schooling but also interact with formal schooling practices, more directly. Indeed, rapid growth and mass subscription to outside-school academic support mean that tutoring has become 'incorporated into the broader culture of education' (Mori \& Baker, 2010, p. 36) - not only do young people seek this support, but also, in some societies, schoolteachers have been identified as active suppliers of these educational services. For example, in Cambodia, Dawson (2009) found that schoolteachers force their students to solicit tutoring support from them after schooling hours. Reflecting on this case and others where similar practices prevail, Bray and Kwo (2013) argue that private tutoring functions as a 'hidden form of privatisation behind the façade of public education systems' and, as such, has serious implications for social justice (p. 480).

This article contributes to these ongoing discussions by exploring the ways in which private tutoring businesses gain social legitimacy in an Indian context. Specifically, it draws on ethnographic data - produced through my interactions with tutors, school teachers, teacher-tutors, students and their parents in Dehradun in 2014 15 - to investigate tutoring practices, in relation to formal schooling. In the process of unveiling tutorial centres' institutional and affective strategies for securing social validity as education centres, this article offers a nuanced understanding of the dynamic interactions between formal schooling practices and informal (tutoring or 'shadow') provisions - and alludes to the impact of this - within the empirical context.

In what follows, I will provide an overview of the literature on the social legitimacy of private tutoring. Next, I will outline the Indian context in which this study is empirically situated and the methods I adopted for data production and analysis. I will then present key tutoring practices and show how these are associated in intricate ways with formal schooling practices, before synthesising these findings to showcase the project of social legitimacy of private tutoring - and its significance - in the presented Indian case.

\section{Social legitimacy of private tutoring - and its connection to formal education}

Private tutoring is commonly referred to as a 'shadow' of mainstream education for many reasons, but primarily because tutoring practices cannot survive without formal education; the former changes its structure and practices as per the transformations occurring in the latter. Through alluding to the dependence of private tutoring on formal schooling, this metaphor helps with not only identifying a variety of educational services - such as cram schools, individual and group support, home tuition, and online lessons - as part of tutoring provision, but also signals the relevance of private tutoring in association with formal schooling practices.

Some scholars view the social legitimacy of private tutoring in terms of the rising demands for individualised educational support in contemporary societies where educational credentials are construed as critical determinants of future life opportunities (Baker, 2014). Indeed, as indicated earlier, many parents and children consider the 'extra' academic inputs that tutorial centres offer as essential or desirable, depending on the context, for excelling in the school appraisal system (discussed in Bray, 2017). 
The mass adoption of private tutoring is also influenced by the nature of its supply, particularly, and arguably, the transfer of embodied educational resources (for example, teachers) from schools to the tutorial market. Whether in the form of corruption (where schoolteachers force their students to attend after-school paid lessons - see Dawson, 2009) or teacher entrepreneurialism in neoliberal education spaces (where educators consider tutoring and schooling sectors as markets where they sell their services, see, for example, an Indian case in Gupta, 2019), the involvement of trained and qualified teachers in tutoring businesses signifies the quality of the tutoring sector, promoting their value as centres for effective learning (see, Holloway \& Pimlott-Wilson, 2020).

The social legitimacy project of tutoring enterprises is also revealed in their structure. Drawing on a study of edu-businesses in Canada, Janice Aurini (2006) argues that these businesses adopt a 'hybrid institutional framework' - that is, 'by engaging in strategical isomorphism and by responding to new pressures in the technical environment' (p. 83) - to secure legitimacy in the education market. Put simply, instead of complying fully with the structure of the formal education system, tutoring businesses combine attributes from the system with the elements derived from the market demand for academic input in order to be perceived as legitimate teaching and learning centres.

All of these views - the demand, the supply, and the structure - inform the contemporary understanding of private tutoring as a complex phenomenon, intertwined deeply with the formal schooling system. Building on this body of scholarship, this article focuses on tutoring practices (institutional and affective), looking specifically at the ways in which these resemble - and deviate from - formal schooling in an Indian context. The analysis, thus produced, would allow for unveiling the implications of private tutoring for schools as well as for the educational landscape more broadly.

\section{Prevalence and pattern of private tutoring in India}

In India, private tutoring is pervasive. The 2017-18 household survey, conducted under the auspices of the National Statistical Office, reveals that nearly $20 \%$ of students at various educational levels solicit tutoring support (Government of India, 2020). While the exact prevalence of private tutoring is difficult to ascertain, this survey report identifies significant variations in its spread: by state (tutoring enrolment rates of $75.2 \%$ in West Bengal, but only $2.3 \%$ in Telangana, and $4.0 \%$ in Rajasthan, for example), region (26\% of the urban population as compared to $17.3 \%$ of the rural-based students solicit tutoring support), and by gender (20.5\% of male and $19 \%$ of female students attend private tutoring). Similar patterns were reported in Sujatha (2014), in their study conducted with 4,031 students in 49 schools across Kerala, Maharashtra, Andhra Pradesh, and Uttar Pradesh. In addition, Sujatha found that students enrolled in private unaided schools, that usually charge high fees and are often perceived to offer better educational support, are much more likely to solicit tuition than their counterparts studying at either government or government-aided schools - both of which charge significantly lower fees. These patterns allude to the role of private tutoring in reproducing the inequality in accessing quality education (see Sujatha, 2014).

The growing adoption of tutoring services across families emerges from "the general conviction among the parents that private tuition is "unavoidable" if it can be 
at all afforded' (Sen, 2009, p. 13). This perceived necessity of tutoring support is felt much more greatly at the secondary (with $30.2 \%$ of students attending private tutoring) rather than at primary educational levels (with $16.4 \%$ undertaking tutoring support) (Government of India, 2020). As a result, many small-scale - mixed methods and qualitative studies - have focused on private tutoring experiences between Grades 8-12. In their study conducted in Bengaluru, Ghosh and Bray (2018) found that many students seek private tutoring to prepare well for the competitive and high-stakes assessments conducted at Grade 10 and 12. The authors identify credentialism - the rising significance of educational credentials for labour market entry and for realising social mobility more broadly (as mentioned earlier, see Brown, 2001) - as the key driver of the decision students and their families make to subscribe to tutoring services (also discussed in Gupta, 2020). In another article that focuses on West Bengal, the authors claim that 'dissatisfaction due to culture of fear and/or lack of trust' from the schooling system creates demand for private tutoring (see, Ghosh \& Bray, 2020, p. 14).

Studies have also shown the profound impact of tutoring on the educational landscape more broadly and its implications for formal schooling more specifically. For example, Bhorkar and Bray (2018), drawing on their study in Maharashtra, argue that while tutoring appears to supplement the curriculum at elementary levels, it tends to supplant the curriculum at secondary educational levels. They find that many Grade 11 and 12 students find the school syllabi inadequate to assist them with successfully transitioning to higher education. In these educational levels, students tend to rely on coaching support, to not only pass their school tests, but also to ensure success in highly competitive college entrance exams. In another study, Punjabi (2020) argues - based on their research on the pedagogical experiences of Grade 11 aspiring engineers in Delhi - that informal coaching centres are becoming a 'new formal' by 'taking possession of the formal teaching in schools either by training students for school and Board exams or by intruding into the physical spaces of schools by way of school-integration programmes' (p. 36). Punjabi found that students often believe that coaching centres offer 'more strategic and effective ways of teaching than those typical of formal schools' (p. 22). In both of these studies, schools are portrayed as institutions in dire need of reform to be able to successfully compete against tutoring and coaching businesses.

The relationship between private tutoring and formal schooling is also illustrated in the teachers' role as suppliers of tutoring services. Although under the 2009 Right to Education Act, schoolteachers are prohibited from tutoring their schools' students, this practice is still prevalent (see Majumdar, 2014). In private schools, where management enforces strict regulations against teachers offering tutoring support to their own students, many schoolteachers either run their own centre or liaise with private education businesses to provide tutoring to students enrolled in other schoolsmany of these educators align their professional identity as teachers with their role as entrepreneurs in the education market more broadly (Gupta, 2019). Teachers' involvement in private tutoring also positions tutorial centres as potentially 'useful' educational spaces.

As shown here, much of the literature on private tutoring in India has explored the wider pattern (Government of India, 2020; Sujatha, 2014), demand (see Sen, 2009; Gupta, 2020; Ghosh \& Bray, 2018; 2020), and supply (Bhorkar \& Bray, 2018; Gupta, 2019; Punjabi, 2020) side of private tutoring. Each of these studies points to specific implications that tutoring centres have for formal schooling. Contributing to this body of scholarship, this article offers an account of the dynamic between formal (schools) 
and informal (tutorial centres) practices, both institutional and affective. In so doing, it elucidates the ways the latter positions itself in relation to the former, such that both education delivery systems co-exist within the same educational landscape. This analysis demonstrates how tutoring centres organise themselves institutionally in their pursuit to gain social legitimacy in an Indian context.

\section{The study}

This article draws on a range of qualitative data, produced through an educational ethnography, conducted in Dehradun (India) between 2014-15. I interviewed 22 tutors in 12 tutorial centres (tutorial centres in this study are considered as informal educational setups, as compared to schools which are formal institutions of education delivery). Two of these centres were visited more frequently for classroom observations and for informal conversations with tutors and students - I observed 10 tutorial sessions of Grade 10 Mathematics (students aged 15-16 years). Moreover, I interacted with 38 schoolteachers in two private unaided schools and had 'opportunistic chats' (O'Reilly, 2012) with students and teachers during the fieldwork. Some of these teachers also shared their experiences of being part-time tutors. In both schools, I observed ten classroom teaching sessions of Grade 11 Economics (students aged 16-17 years). The data above are supplemented with my interviews with parents in 53 families.

Formal interviews and informal conversations were equally important in this study - particularly, the latter helped to overcome barriers to collecting what might be regarded as sensitive information about private tutoring (the methodological challenges pertaining to unwillingness, due to shame and suspicion, to share information about people's engagement with tutoring is well documented and articulated in Bray, 2010, for example). Such sensitive information, in the empirical case presented here, includes tutors, parents and students being open about their experiences; schoolteachers' acknowledgement of the problems in their own practices, identifying and speaking about the prevalence of private tutoring and sharing opinions about tutoring businesses.

I audio-recorded interviews and kept fieldnotes of informal interactions. Both offered me insights into participants' perceptions and their experiences of teaching and tutoring practices. After the fieldwork, I transcribed the audio recordings and digitalised the fieldnotes. For data analysis, I first coded the transcripts for generating 'concepts and for allocating excerpts of the material to categories' (Flick, 2014, p. 373). This process entailed 'unfolding, unravelling, breaking up, separating, disassembling or fragmenting' the material (Boeiji, 2010, p. 77). Next, I reassembled the transcripts and looked for 'patterns, searching for relationships between the distinguished parts, and finding explanations for what is observed' (Boeiji, 2010, p. 76). The relevant themes that emerged from the analysis about the institutional practices of private tutoring in relation to formal schooling are outlined in the following section. I have used pseudonyms to protect the participants' identities.

\section{Tutoring practices - conforming to the formal schooling system}

All tutorial centres in this study followed a three-layered classification - by subject of study, educational level, and Education Board (henceforth, Board) - to outline their 
academic services. For example, 'Apex Tutorial Centre' - one of the sites where this study was conducted - specifies that it offers tutoring services in 'Physics, Chemistry, Biology, Mathematics, Commerce, and Accountancy' based on the curriculum provided by 'CICSE [Council for the Indian School Certificate Examinations], CBSE [Central Board of Secondary Education], and the State Board [Uttarakhand Board of Secondary Education]' for 'Class VI to XII' [Grade 7 to 12].

Each of these Boards occupies a distinct social space in India's formal education system (see, Gupta, 2018). For example, all the parents in this study compared the fees of schools affiliated with different Boards to argue in various ways that: CICSE schools are for the elite; state board schools serve the poor, whereas CBSE schools cater to mostly the middle fraction of the social class. The majority of tutorial centres in the sample supported the curriculum of CICSE and CBSE, presumably for attracting students from well-off families. Moreover, it was common for centres to charge higher fees for tutoring CICSE curriculum, relatively lower for CBSE and lowest for UBSE - which seems to correspond to the fee-structure of schools affiliated with each of these Boards. This connection between formal schooling practices and the structure of private tutoring is articulated clearly below in an interview excerpt with a tutor.

$[\mathrm{P}]$ arents who can afford to send their children to high-fee schools are more likely to pay for private tutoring ... if they [parents whose children are enrolled in CICSE schools] can pay thousands [as fees] for school, surely, they can cough up a few extra hundred rupees for tuition. (Ashwin, tutor)

Notably, even though most tutors acknowledged that they find the curriculum of different Boards remarkably similar, they still comply with the popular opinion of difference.

Parents and students believe that each Board has different syllabi ... but in my experience of teaching Mathematics for about ten years, I do not see much of a difference ... but we go along with this thinking [that each Board offers a distinct set of curricula]. They [parents and students] prefer it that way. (Rajesh, tutor)

Even though many tutors supplied academic services for more than one Board to maximise their market presence, they would maintain Board-based homogeneity within classrooms, by segregating students by the Board with which their schools were affiliated (see, Gupta, under review). Notably, despite disagreements with the general opinion about differences across Board, tutors in this study complied with the Board-based classification to signify the relevance of their centres in the segregated formal education market.

Furthermore, all tutorial centres also aligned their services to the educational levels and academic subjects offered in schools. Importantly, though, as profit-driven enterprises, tutorial centres could have potentially provided their services for all subjects across all grades. Yet, many provided tutoring and coaching support for specific subjects and often only at secondary educational levels, focusing mostly on Grade 9 to 12 (this aligns with the data presented in Government of India, 2020; Bhorkar \& Bray, 2018).

We provide tuition for Science and Mathematics from Grade 6 to 12. However, mostly Grade 9-12 students come to us asking for tuition in physics, chemistry, mathematics, and biology. We have sessions for junior secondary (Grade 6 to 8 ) twice a week and daily sessions for senior secondary (Grade 9 to 12 ). (Avinash, tutor) 
In the formal education system in India, while academic achievements at all grades are deemed important, the stakes are fairly low at elementary levels and substantially high at more advanced grades. The marks obtained at Grade 10 determine the subject choice (for example, Arts, Science, or Social science) for the next phase of study, and the results of Grade 12 shape the transition to higher education and future career trajectories. Final assessments at these two educational levels are colloquially referred to as Board exams. Also, all participants felt that the higher the level, the more rigorous the assessments became. Considering the stakes and the academic demands on the students to excel, most parents and tutors I spoke with felt that while it is 'optional' at elementary levels, it is 'essential' at the secondary levels for children to receive regular tutoring support. The extent to which tutoring was felt to be required in different households depended primarily on - as shown below - parents' ability to assist their children in academic work (also see, Gupta 2020 for discussion on parental investment in education and differential distribution of cultural capital in middle-class families in India).

I am more confident to teach the young one [child in Grade 3] at home. If I don't have time, his father or elder brother cover for me. So, he does not need tutoring as such, but the older one [Grade 10] needs regular tuition. It's a difficult grade, you know, with the Board exam and all. (Rakhi, parent)

The educational level in which a child is studying makes a lot of difference. The first five years of schooling are very basic, but when the child reaches Grade 6, courses become a bit more demanding. From Grade 9 onward, they become even more challenging for students to cope with the rigour that is expected from them when they prepare for assessments. At higher levels, concepts are more difficult to grasp, and students need to practise more and more to master the application of the concepts. (Rajesh, tutor)

Responding to this dynamic produced by the formal education system, most tutors offered tutorial support at secondary educational levels. Also, they often advised which some parents in the sample complied to - to invest in tutoring at a young age. Parents who made this decision argued that doing so would provide their children with a 'solid foundation' of academic subjects and ensure an easy transition to higher grades.

Notably, as exemplified in the excerpt below, more sustained tutoring support was felt to be necessary for certain subjects but not for others.

No one fails in Arts and Music. Hindi, English, and History are a bit tricky. I usually memorise the answers and prepare for the exam by writing all the answers in a notebook as fast as I can. It is Science and Mathematics that one really needs to prepare for. I need to memorise some concepts, but then I also have to know how to use them for answering different questions. (Anshul, Grade 9 student)

Other students voiced similar opinions about the degree of effort required to prepare for tests in different subjects. They believed that exam questions in Hindi, English and History were textbook-driven and could be prepared for by rote-learning, whereas other subjects such as Science and Mathematics demanded a deeper understanding of concepts. Students also felt that while the former were 'easy' subjects, the latter mattered more, as most students I interacted with aspired for careers in engineering and medicine. This was reflected in interviews with parents, too (see Gupta, 2020). Correspondingly, the majority of tutorial centres offered academic support for these more 'demanding' and 'challenging' subjects. 
The analysis presented here shows the specific ways in which private tutoring adheres to the formal schooling practices and responds to the social perceptions about education that these practices produce. Notably, though, as shown here, instead of completely mirroring the formal education system as it is, tutorial centres mimic it only to the extent to - and ways in which - their services are perceived by parents and students as relevant, useful, and desirable.

\section{Tutoring practices - deviating from typical schooling norms}

Although all 12 tutorial centres that participated in this study embraced a few practices of formal schooling, they also deviated from - and, in doing so, challenged other typical schooling norms.

\section{Teaching credentials}

While educators in school settings argued that their educational qualifications firstly indicated their 'knowledge of relevant subjects', 'teaching skills' and 'overall competency', and secondly, equipped them for a teaching profession, in the private tutoring settings, educators' credentials were premised on a wider set of claims. Tutors (including teacher-tutors) maintained that factors other than educational credentials were more valued signifiers of their preparedness for performing a tutoring role. For example, teacher-tutors stressed that their insider understanding of the education system (such as their knowledge of syllabi, assessment patterns and processes) are prized in the tutorial market.

\footnotetext{
They [schoolteachers] are well-versed with the routine of setting a question paper, evaluating and measuring students' progress. Schoolteachers are skilled, and as insiders to the system, they are likely to have a nuanced understanding of the changes made by the Education Boards to both syllabi and assessment patterns. (Akash, teacher-tutor)
}

Most full-time tutors foregrounded their success in producing academically excellent results as an indicator of their teaching credential. For example, Arvind started tutoring when he was in high school. He earned his reputation in the tutorial market gradually by producing batches of high-performing students. Arvind's students gave him credit for their exceptional performance in high-stakes exams, in interviews that were published in local newspapers. Many full-time tutors maintained that one's educational qualifications do not determine their teaching credentials.

\footnotetext{
You are likely to meet an 'unqualified' but an excellent educator in tuition classes ... schoolteachers may have 'right degrees' but [they] rarely have the passion for teaching. Teaching potential has nothing to do with your certificates ... I don't have degrees to prove my teaching ability, but I'm committed to providing my students with everything they need ... (Arvind, tutor)
}

Arvind's impression of schoolteachers was in alignment with schoolteachers' own perception of the efficacy of their work at school. During interviews, teachers characterised their work as 'prescribed' for meeting 'time-bound targets'. Amidst the 'intense pressure of finishing the syllabus and conducting exams' and the 'lack of institutional support', many of them felt that they seldom used their knowledge and skills effectively for teaching. 
I learned a lot about the psychology of children during our [teacher training] programme ...

those lessons seem theoretical now and frankly not very useful in my everyday teaching ... we

learned using interactive teaching methods ... those aren't practical. (Hema, schoolteacher)

Many teachers also confessed that the limited scope for using innovative pedagogical methods and interacting with students (discussed later in detail) hinders their ability to help their students. Tutors, on the contrary, not only provided academic support with greater flexibility, but they also seemed more invested in providing holistic support to their students:

\begin{abstract}
... a more pressing concern for a middle-class child is not just passing school tests, it is to make a successful transition to higher education. I speak from my own experience - it is not easy to secure a place in a reputed college of engineering or medicine these days. I talk to my students about how to prepare - academically, emotionally, and financially - for these brutally competitive tests. (Prashant, tutor)
\end{abstract}

The transition from schooling to higher education can be stressful for many young people, especially those who aspire to pursue a sought-after degree programme in a reputed college (see Punjabi, 2020). Middle-class parents often invest heavily in their children's schooling to ensure that their children are able to compete in college entrance tests (Gupta, 2020). This, in turn, adds to the pressure that many students I spoke with, felt. Schoolteachers were aware of these pressures, but they lacked the institutional infrastructure to support their students in their ordeal. As a recent engineering graduate, Prashant had lived these experiences and had an acute understanding of the failure of family and schools in supporting students for making this transition. Recognising the vulnerable position of many of his students, Prashant would advise them on: the cost of different colleges; useful academic resources and the emotional readiness required for prepping for these competitive exams. Indeed, in these instances, tutoring had supplanted the role and purpose of formal schooling.

\title{
Teacher-student relationship
}

Many students I interacted with about their experiences with private tutoring spoke at length about their relationship with tutors - most of these exchanges also involved frequent comparison with the teacher-student relationship at school. The majority of teachers shared the view that 'despite [their] willingness, [they] seldom have the opportunity to engage with students on a personal level':

While I think it is a good idea, I simply do not have time to talk to my students. We [fellow teachers] have so much to do every day [pointing at the management prescribed teaching schedule] that it is actually very difficult to find space to interact with students and connect with them informally. (Rakhi, schoolteacher)

Teachers would typically interact with students after their lessons - either about disciplinary issues or assessment-related topics (for example, the syllabus for upcoming tests and examination formats). While a few teachers felt that they could not interact informally with their students, others deemed that they should not do it, as doing so would be against the 'school's etiquette'. 
During interviews, many teachers maintained that 'the relationship between students and teachers should be as the one between a guru and a shishya (disciple)'. This traditional hierarchical model presumes that teachers are the source of wisdom and students are its passive recipient. The manifestation of this hierarchical model could be seen in honorific practices. In schools, students referred to a male teacher as 'sir' and a female teacher as 'ma'am'. Introduced during the British colonial period, these terms signify the higher authority of teachers.

I think rather than being friendly, it is more important to discipline the kids of today's generation. They are out of control if you ask me...they don't listen to their parents and don't pay attention in the classroom either. (Samay, schoolteacher)

Many schoolteachers exerted their unwillingness to further their interactions with students beyond 'formal' and 'distanced' exchanges. They feared that if they became 'friendly', it would encourage students to be a 'nuisance', hinder the classroom discipline, and adversely affect their regular teaching tasks. This concerted effort on the teachers' part was reflected in how students felt about their relationship with teachers.

Other than saying 'good morning', 'good afternoon', 'sorry', and 'thank you', we do not really speak to teachers in school. Only those who are 'disturbing elements' get to 'talk' to the teachers (laughs). (Manpreet, Grade 10 student)

Both teachers and students used the term 'disturbing elements' to refer to the students who would 'upset the order' in the classroom. Teachers often penalised these behaviours by scolding the offending students and informing their parents about it. In this environment, students lacked the agency and desire to initiate conversations with their teachers.

Tutors approached their relationship with students significantly differently to schoolteachers, by, first and foremost, dismantling the assumed authoritative hierarchy between them and their students discursively (as shown below) - this was particularly valued by students.

In the tuition [centre], we can share anything with Arvind $d a$ (big brother) [...] It could be about exam pressure or stress or even personal problems. He is more like a friend; he understands what we go through...(Manpreet, Grade 10 student)

As indicated above, in all tutorial centres, students used Da/Bhaiya (big brother) or $\mathrm{Di} / \mathrm{Didi}$ (big sister) to address their tutors. Embedded in the social milieu of Indian society, these terms signal the mirroring of familial bonds, implying that tutors assume the role of 'elder sibling' to their students.

Furthermore, tutors often shared with students their stories and experiences. They would interact with students during breaks and after tutorial sessions and welcome students to share their views - often related to the session, but also on personal matters. For example, Ravi, a physics tutor, shared the following, in one of his sessions.

I had to take care of my whole family when I was your age. Still, I did not quit school. I worked hard and got into college. Now, see, I am teaching you. I know that it is challenging to keep up with grades when the competition is so high. But think about where this work will take you. If I could do it, you surely can. 
Ravi's story, told in response to a student speaking about the stress he feels to excel academically, offered an avenue for students to relate to Ravi on a personal level. Similarly, Utkarsh - another tutor - would often share his struggles with learning specific concepts and discuss how he overcame those hardships. While sharing these profoundly emotive personal stories was not part of the curriculum, this had the potential for a lasting impact and often helped to form a trusted bond between tutors and students during and beyond schooling years. For example, it was quite common to witness former students coming along to tutorial centres with sweets to celebrate their life milestones with their tutors and discuss future career options.

\section{Pedagogical approach}

Schools and tutorial centres in this study had very different approaches to teaching and supporting learning. Most schoolteachers subscribed to 'textbook centric' pedagogy to give themselves the best chance of completing the syllabus within the prescribed timeframe. They opted for lecturing as the main teaching method, often leaving limited scope and space for students' engagement. In all the sessions I observed in both schools, teachers read aloud the definition of key terms, formula, and examples to illustrate the concepts. They jotted down formulae on the whiteboard and solved a few questions from the 'exercise section' of a chapter and set other questions for homework. Students noted down everything the teacher said. No students sought clarification or asked questions. After attending a teaching session, I spoke with a few students about their learning experience in school. Many were in agreement with Hina when she said:

In school, we are supposed to write things down in our notebook, following exactly the same structure as the teacher indicates. We do not need to know everything that we write, still, those who fail to do so are penalised the next day...so we just take note of whatever teachers say without quite putting our minds to what we write. (Hina, Grade 11 student)

While some teachers attempted to engage their students by using participatory teaching methods, these were often discontinued on account of being 'too timeconsuming' and 'hindering the process of meeting set targets'. Teachers admitted that their typical methods were inadequate to foster effective learning (see Gupta, 2019). Text-book centric teaching methods also promoted the culture of rote learning among students - this was problematised by many tutors during interviews.

In contrast to these popular pedagogical approaches seen in the formal classrooms, all tutors emphasised that they strive for orchestrating 'meaningful', and 'engaging' discussions in tutoring sessions to stimulate 'critical' and 'sharp' thinking among students. For example, in a typical tutorial session, Ravi would take the first 15 minutes to recite key definitions, concepts, and write formula on the whiteboard. $\mathrm{He}$ would then use real-life examples to explain the concepts. In the next 20-25 minutes, students were given the opportunity to ask questions, and Ravi helped them to apply their understanding to solve a variety of problems. Students also sought clarifications along the way. In the final 30 minutes, Ravi welcomed students to suggest questions from the textbooks - which at times were, as students identified, 'homework from school' - and solved them by inviting suggestions from the students themselves.

When compared with school, all the students I spoke with felt supported and encouraged in tutorial centres, and they admitted that their tutorial notes were more 'useful' in their preparation for Board exams. Notably, teachers' perception of the 
students' reliance on private tutoring created a new dynamic in classrooms, which had serious implications for teachers' work.

As a teacher, I want my students' attention, but in the past few years, I have noticed that the students are not at all responsive in the classroom. When I tell them to pay attention...no response from them really annoys me. I know their tuition teachers (tutors) might have already taught them those things. [Pause] Anyway, I am just here to complete the syllabus...

(Kalpana, schoolteacher)

Many schoolteachers interpreted the above-mentioned behaviour of their students as 'disrespectful', 'insincere', and 'rude'. Subsequently, the teachers felt underappreciated by their students. They adopted indifferent attitudes toward their students' unresponsiveness despite having identified their own teaching practices as ineffective. Eventually, they refrained from making any improvements to their own teaching approach.

\section{Conclusion}

This article has offered insights into the project of social legitimacy of private tutoring by focusing on its institutional practices with reference to that of the formal schooling system in an Indian context. It has shown that tutoring practices strategically conform to and purposely deviate from the prevalent formal schooling practices, to respond effectively to the market demands for beyond-school educational support. This finding can be compared to Aurini's (2006) suggestion of edu-businesses using a 'hybrid institutional framework' for their operation (as discussed earlier), where private tutoring complies with and challenges the formal education system simultaneously. Furthermore, instead of merely shadowing the formal education system, I argue that tutorial centres operate as active agents of education delivery that function alongside - and in relation to - mainstream schools.

This investigation has also illustrated that while conforming to formal schooling aids the project of social legitimacy of tutorial centres, it also reveals deeply problematic hidden facets - such as the disparity and segregation in the form of Board dynamics, primacy of academic credentials and the high stakes of performing at specific levels and particular subjects - of mainstream schooling. The carefully planned mimicking of the formal education system signifies the reproduction of not merely socio-demographic differences but also - as shown here - the intensive credentialism and disparate nature of formal schooling, through tutorial businesses.

Conforming to the mainstream education system helps tutoring businesses to project their image as academically relevant additions to formal schooling, whereas it is the deviation from other prevalent schooling practices that strengthens their position as desirable spaces for teaching and learning. For example, tutors tend to: foreground their ability to help students to achieve academically rather than their own educational qualifications as a measure of their credential; strive for developing familial and friendly connections with students instead of following the distanced and hierarchical model of formal schools and adopt student-centric as opposed to textbook driven teaching approaches to foster learning. These approaches are instrumental in shaping societal perceptions of tutorial centres as trusted, reliable, and useful educational spaces. Hence, private tutoring gains social legitimacy not just by using valued pedagogical approaches (as also shown in Punjabi, 2020; Sriprakash et al., 
2016) but also through responding to the affective needs of students more effectively than schools appear to do.

Through showing the nuances of the relationship between the 'school' and the 'shadow', this article argues that private tutoring, in the case presented here, may be conceptualised by its co-existence with schooling, as a critique of how formal schooling is conducted in India. For example, it shows how in the schooling context where teachers' accountability is determined by their ability to meet deadlines for prescribed tasks and targets set by the school management - schoolteachers often find additional investment in classroom teaching, cultivating relationships with their students and preparing tools for fostering learning, as wasteful. Tutors recognise - and indeed capitalise on - the teaching and learning deficit that this culture of formal schooling, in this context, produces. This process strengthens the role of private tutoring - and relatedly weakens the importance of formal schooling - as academic centres of teaching and learning. Moreover, the evidence suggests that, as already pressured to meet strict targets and feeling devalued by students in the classrooms, schoolteachers are discouraged from resolving problematic schooling practices that they themselves identify as such. This dynamic creates avenues for tutoring businesses to flourish further and - in significant ways - renders them as an inseparable part of mainstream education, alongside schools.

This article recognises private tutoring as an influential actor in shaping the current schooling system and its practices. It reflects a relatively small group of schools and tutorial centres. The institutions that represent these education systems are heterogeneous. Given the diversity and disparate nature of formal schooling within India and beyond, it is likely that practices of other schools and tutorial businesses are different from the ones outlined in this article. Bringing forth this diversity and comparing it with the case presented here would help to advance the understanding of dynamics between formal schooling and its 'shadow' more comprehensively and globally.

\section{References}

Aurini, J. (2006). Crafting legitimation projects: An institutional analysis of private education businesses. Sociological Forum, 21(1), 83-111.

Baker, D. (2014). The schooled society: The educational transformation of global culture. Stanford, CA: Stanford University Press.

Bhorkar, S. \& Bray, M. (2018). The expansion and roles of private tutoring in India: From supplementation to supplantation. International Journal of Educational Development, 62, 148156.

Boeije, H. (2010). Analysis in qualitative research. Los Angeles, CA: Sage.

Bray, M. (2010). Researching shadow education: Methodological challenges and directions. Asia Pacific Education Review, 11, 3-13.

Bray, M. (2017). Schooling and its supplements: Changing global patterns and implications for comparative education. Comparative Education Review, 62(3), 469-491.

Bray, M. \& Kwo, O. (2013). Behind the façade of fee-free education: Shadow education and its implications for social justice. Oxford Review of Education, 39(4), 480-497.

Brown, D. K. (2001). The social sources of educational credentialism: Status cultures, labor markets, and organisations. Sociology of education, 74, 19-34. doi:10.2307/2673251 
Dawson, W. (2009). The tricks of the teacher: Shadow education and corruption in Cambodia. In S.P. Heyneman (Ed.), Buying your way into heaven: Education and corruption in international perspective (pp. 51-74). Rotterdam, the Netherlands: Sense Publishers

Flick, U. (2014). An introduction to qualitative research (5th ed.). LA: Sage.

Ghosh, P. \& Bray, M. (2018). Credentialism and demand for private supplementary tutoring. International Journal of Comparative Education and Development, 20(1), 33-50.

Ghosh, P. \& Bray, M. (2020). School systems as breeding grounds for shadow education: Factors contributing to private supplementary tutoring in West Bengal, India. Eur J Educ. DOI: 10.1111/ejed.12412

Government of India (2020). Household social consumption on education in India. New Delhi: National Statistical Office.

Gupta, A. (2018). Shadow education in contemporary India: production, organisation and implications of private tutoring. Unpublished $\mathrm{PhD}$ thesis, National University of Singapore, Singapore.

Gupta, A. (2019). Teacher-entrepreneurialism: a case of teacher identity formation in neoliberalizing education space in contemporary India. Critical Studies in Education, DOI: $10.1080 / 17508487.2019 .1708765$

Gupta, A. (2020). Heterogeneous middle-class and disparate educational advantage: parental investment in their children's schooling in Dehradun, India. British Journal of Sociology of Education, 41(1), 48-63.

Gupta, A. (under review). Behind the shadow: Empirical scrutiny of the shadowing process of private tutoring in India. Educational Review.

Holloway, S. L. \& Pimlott-Wilson, H. (2020). Marketising private tuition: Representations of tutors' competence, entrepreneurial opportunities and service legitimation in home tutoring business manuals. British Educational Research Journal, 46(1), 205-221.

Majumdar, M. (2014). The shadow school system and new class divisions in India. Working Paper Series, TRG Poverty \& Education. London: Max Weber Stiftung.

Mori, I. \& Baker, D. (2010). The origin of universal shadow education: What the supplemental education phenomenon tells us about the postmodern institution of education. Asia Pacific Education Review, 11, 36-48.

O’Reilly, K. (2012). Ethnographic methods (2nd ed.). Abingdon: Routledge.

Park, H., Byun, S. Y., \& Kim, K. K. (2011). Parental involvement and students' cognitive outcomes in Korea: Focusing on private tutoring. Sociology of Education, 84(1), 3-22.

Punjabi, S. (2020). Is shadow education becoming the 'new' formal? Effects of pedagogical approaches of IIT-JEE coaching on school education in the city of Delhi. Contemporary Education Dialogue, 17(1), 14-44.

Sen, A. (2009). Introduction: Primary schooling in West Bengal. In K. Rana (Coordinator), The Pratichi education report II: Primary education in West Bengal-changes and challenges. New Delhi: Pratichi Trust.

Sriprakash, A., Proctor, H., \& Hu, B. (2016). Visible pedagogic work: Parenting, private tutoring and educational advantage in Australia. Discourse: Studies in the Cultural Politics of Education, 37(3), 426-441.

Sujatha, K. (2014). Private tuition in India: Trends and issues, Revue Internationale d'éducation de Sèvres. Retrieved from: http://ries.revues.org/3796. 